\title{
Musculoskeletal Involvement in Children With Gastroschisis and Omphalocele
}

\author{
By Randall T. Loder and Jean-Paul Guiboux \\ Ann Arbor, Michigan
}

\begin{abstract}
- A review of 58 children with gastroschisis and 8 children with omphalocele showed 14 musculoskeletal problems in 11 children. These problems consisted of limb deformities in 6 children, spinal deformities in 4 children, and osteopenia in 3 children, with 1 of the osteopenic children developing pathological fractures. About one third $(5 / 14)$ of the problems were arthrogrypotic in nature. The remainder were mild digital deformities, developmental or spondylodysplastic scolioses, and, rarely, congenital spinal deformities. Copyright 11993 by W.B. Saunders Company
\end{abstract}

INDEX WORDS: Gastroschisis; omphalocele; musculoskeletal problems; spinal deformities; arthrogryposis.

C ONGENITAL abdominal wall defects can be defined as eviscerated organs not covered by normal skin. ${ }^{1}$ There are three distinct types: omphalocele, gastroschisis, and umbilical cord hernia. ${ }^{1,2} \mathrm{Om}$ phalocele and gastroschisis are by far the most severe. An omphalocele is a defect of the abdominal wall at the umbilicus with herniation of abdominal contents, covered by a sac of amnion and chorion. The rectus muscles insert far apart on the costal margins..$^{1,3}$ Its reported incidence is 1 in $4,175^{4}$ to 1 in $6,000^{3}$ live births. A gastroschisis is an abdominal wall defect adjacent to the umbilical cord (usually to the right of the midline). The defect has no sac or sac remnant, and the rectus muscles meet in the midline at the xiphoid. ${ }^{1,5}$ Its reported incidence is 1 in $12,328^{4}$ to 1 in $30,000^{3}$ live births. It has, however, increased in incidence in the last three decades ${ }^{5}$ to the point that in recent series gastroschisis is twice as frequent as omphalocele. 6,7

Until the late 1960s, many children born with these defects did not survive. ${ }^{4}$ With increasing survival rates in these children (especially those with gastroschisis), ${ }^{1}$ 5,8 many can be expected to lead normal lives in the absence of other major congenital malformations or syndromes. It has recently been shown that children with major lower genitourinary tract anomalies (bladder or cloacal exstrophy) can have orthopedic problcms and congenital spinal deformities.9,10 To our

From the Section of Orthopaedic Surgery, University of Michigan School of Medicine, Ann Arbor, MI.

Date accepted: November 5, 1991

Address reprint requests to R.T. Loder, MD, University of Michigan, Section of Orthopaedic Surgery, 1500 E Medical Center Dr, 2912

Taubman Center, Box 0328, Ann Arbor, MI 48109-0328.

Copyright 11993 by W.B. Saunders Company

0022-3468/93/2804-0013\$03.00/0 knowledge, however, no one has investigated the presence or absence of musculoskeletal problems and/or congenital deformities in children with serious congenital abdominal wall defects. Since many of these children are now living, it was the purpose of this study to investigate the presence or absence of musculoskeletal problems in children with omphalocele and gastroschisis at the authors' institution.

\section{MATERIAL AND METHODS}

Sixty-six patients born with gastroschisis or omphalocele between the years 1975 to 1990 inclusive were identified at the University of Michigan C. S. Mott Children's Hospital. Children with umbilical cord hernias were not included in this review. There were 58 children with gastroschisis ( 30 boys, 28 girls) and 8 children with omphalocele ( 3 boys, 5 girls). A retrospective review of the charts and radiographs of these children was undertaken to determine primary diagnosis (gastroschisis or omphalocele), sex, other associated developmental or congenital problems, and the presence or absence of musculoskeletal problems. The primary diagnosis was determined by the pediatric surgeons operative note at the time of abdominal wall closure.

Sixty-two of the 66 patients had radiographs ( 55 with gastroschisis and 7 with omphalocele). The radiographs were reviewed to determine the presence or absence of any congenital spinal deformities on chest or abdominal radiographs. If other portions of the skeleton had been imaged, these radiographs were also reviewed. The radiographs reviewed were: babygrams (20 children), chest radiographs ( 40 children), abdominal radiographs ( 35 children), intravenous pyelogram ( 1 child), extremity radiographs (35 children), scoliosis radiographs ( 2 children), and skeletal survey ( 1 child). Many children had more than one type which were reviewed, accounting for 112 studies in 62 children. The most recent radiograph (oldest age) was reviewed for each child, although $84 \%$ had been performed within the child's first year of life.

\section{RESULTS}

Overall there were 11 children (17\%) with 14 musculoskeletal problems. These were divided into limb deformities, spinal deformities, and metabolic problems. The limb deformities comprised three children with arthrogryposis, two children with digital deformities, and one child with a congenital knee subluxation. Two of the children with arthrogryposis had a gastroschisis. In one child, the involvement was primarily upper extremity with bilateral elbow extension and wrist flexion contractures, which were treated nonoperatively. In the other child the involvement was primarily lower extremity with bilateral club feet (treated operatively) and a knee flexion contracture (treated with serial casting). One child with an 
omphalocele had a contractural arachnodactyly. The two digital deformities occurred in a child with a gastroschisis who had a partial syndactyly of the second and third toes, and another child with an omphalocele who had an absent thumb distal phalanx. These two children died shortly after birth because of other severe congenital deformities. The final limb deformity was a congenital knee subluxation in a child with an omphalocele (Fig 1).

The spinal deformities occurred in one child with gastroschisis and three children with omphalocele. The child with a gastroschisis demonstrated a thoracolumbar scoliosis (T6-L3) at birth of $46^{\circ}$ without congenital vertebral malformations. This child died shortly after birth from severe pulmonary hypoplasia. One child with an omphalocele demonstrated at birth a severe lordoscoliosis ( $78^{\circ}$ lordosis, $90^{\circ}$ scoliosis from T5-L3) with multiple vertebral anomalies (Fig 2). This child also died shortly after birth from associated anomalies including entire ventral body wall disruption with total exstrophy of the heart and lungs. There were two other children with omphalocele (who survived) and had spinal deformities. One showed a very mild scoliosis and associated lumbar platyspondyly. The other child had an associated congenital vesicovaginal-rectal fistula and developed an idiopathic-like scoliosis (Fig 3), which eventually required posterior spinal fusion. Congenital spinal malformations were radiographically present in only one child (previously described, Fig 2). This was determined upon review of babygrams in 20 children, chest with or without abdominal radiographs in 39 children, and 2 children with scoliosis radiographs. This gives an incidence of congenital vertebral anomalies in this patient population of approximately $1 \%$.

Metabolic problems occurred in three children with severe nutritional difficulties and osteopenia on plain radiographs. One child with gastroschisis required home parenteral hyperalimentation secondary to a severe short gut syndrome due to superior mesenteric artery occlusion. Another child with gastroschisis and prematurity had nutritional rickets, and developed pathological fractures of the right proximal humerus, right proximal tibia, left proximal femur, and left distal radius at 3 months of age. A third child with gastroschisis had a prolonged course with necrotizing enterocolitis and secondary nutritional difficulties.

In 42 children, the pelvis and hips could be clearly seen on the abdominal radiugraphs or babygrams.
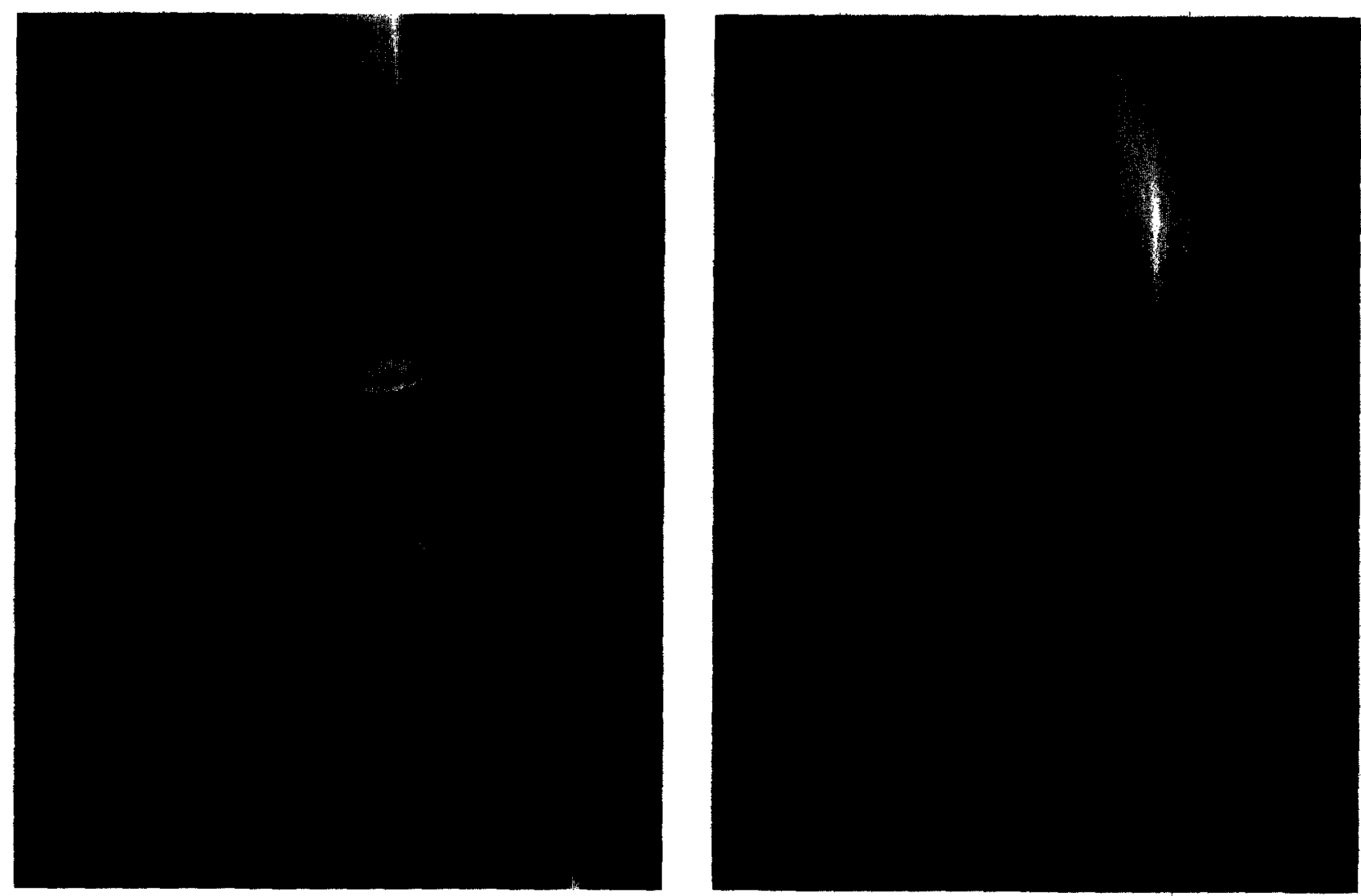

Fig 1. Radiographs of the knee in a 17-year-old boy with an omphalocele demonstrating a congenital lateral tibial subluxation and patellar dislocation. (A) Anteroposterior radiograph. (B) Lateral radiograph. 

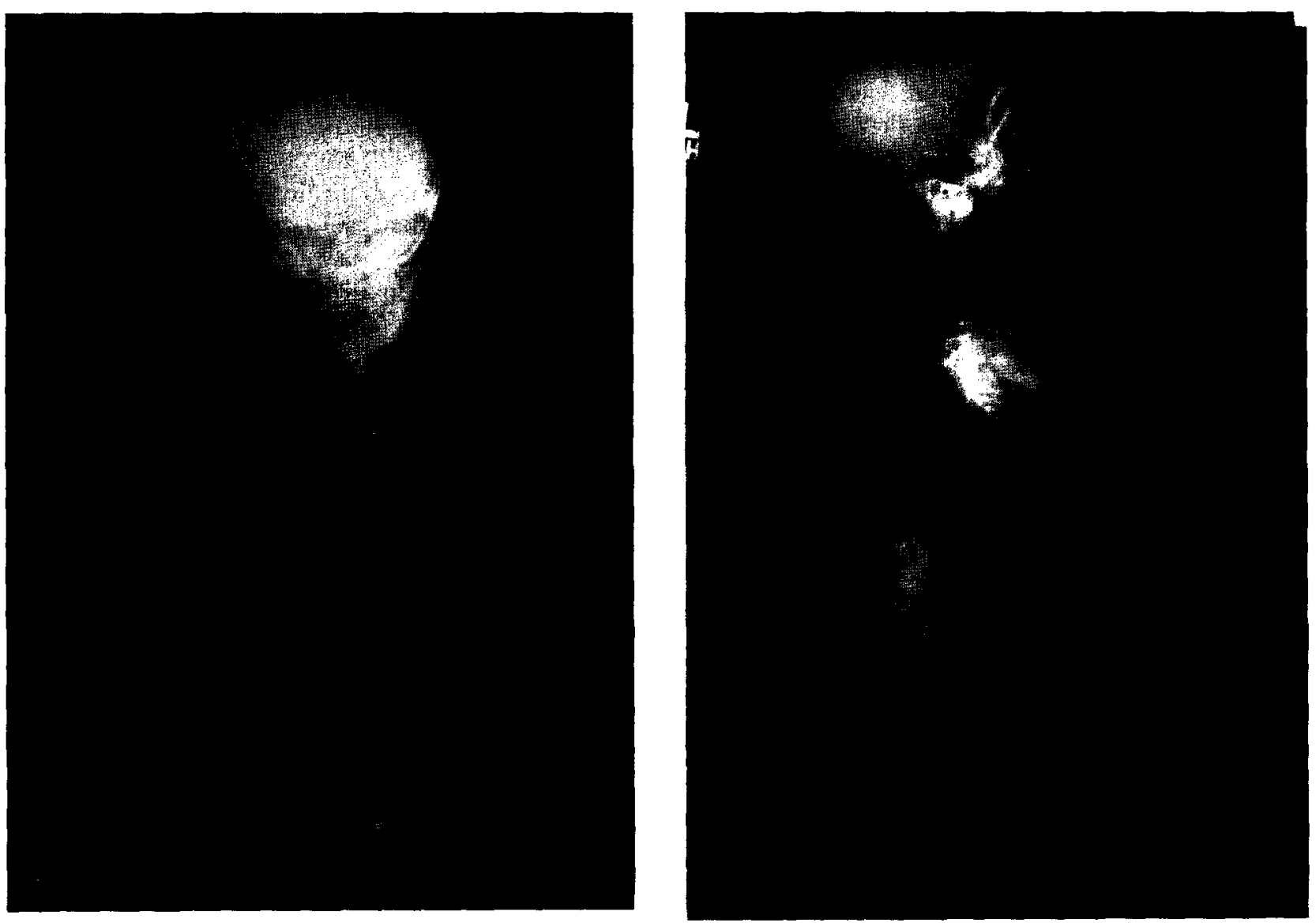

Fig 2. Radiographs (babygram) postmortem of a child with omphalocele, and sternal disruption with exstrophy of the heart and lungs (pentalogy of Cantrell). Note the severe lordoscoliosis and the multiple vertebral and rib anomalies (arrow). (A) Anteroposterior radiograph. (B) Lateral radiograph.

Although the majority were within the first year of life, no hip dysplasia or sacral/pelvic anomalies could be identified. Review of all the other extremity radiographs was also normal except as previously mentioned.

A summary of the musculoskeletal problems is shown in Table 1. The congenital anomalies and developmental problems in other organ systems are shown in Table 2 . Five of the 8 children with omphalocele $(63 \%)$ had 8 associated conditions, whereas 16 of the 58 children with gastroschisis (26\%) had 20 associated problems.

\section{DISCUSSION}

The $17 \%$ incidence of musculoskeletal problems in this series of children with gastroschisis and omphalocele is not as high as seen in some other abdominal anomalies. Greene et $\mathrm{al}^{9}$ recently reported a $100 \%$ incidence of musculoskeletal problems in children with cloacal exstrophy. Children with the prune-belly syndrome are also known to have musculoskeletal involvement in one third to one half of cases. ${ }^{11,12}$
Arthrogrypotic deformitics were present in this series in 5 children (8\%), which is much higher than the $0.03 \%$ overall incidence of arthrogryposis. ${ }^{13} \mathrm{We}$ feel that the $17 \%$ incidence of all musculoskeletal problems is much higher than the expected incidence in a population of normal children, and that an association does exist.

To understand these abdominal defects and their associated anomalies, one must understand their embryology. The abdominal wall starts to form embryologically around the fourth week of gestation. ${ }^{1.14}$ At the end of the third week (day 20 to 23) the flat three-layered embryonic disc develops head and tail folds. The development of an omphalocele is felt to be a primary migration failure of one of the body folds during the fourth week of gestation.,15 The most common omphalocele results from a failure of the lateral fold. If there is a failure of the cephalic fold, then a supraumbilical omphalocele syndrome can develop (eg, Cantrell's pentalogy). If there is a failure of the caudal fold, then an infraumbilical omphalocele syndrome can develop (cg, associated with cloa- 


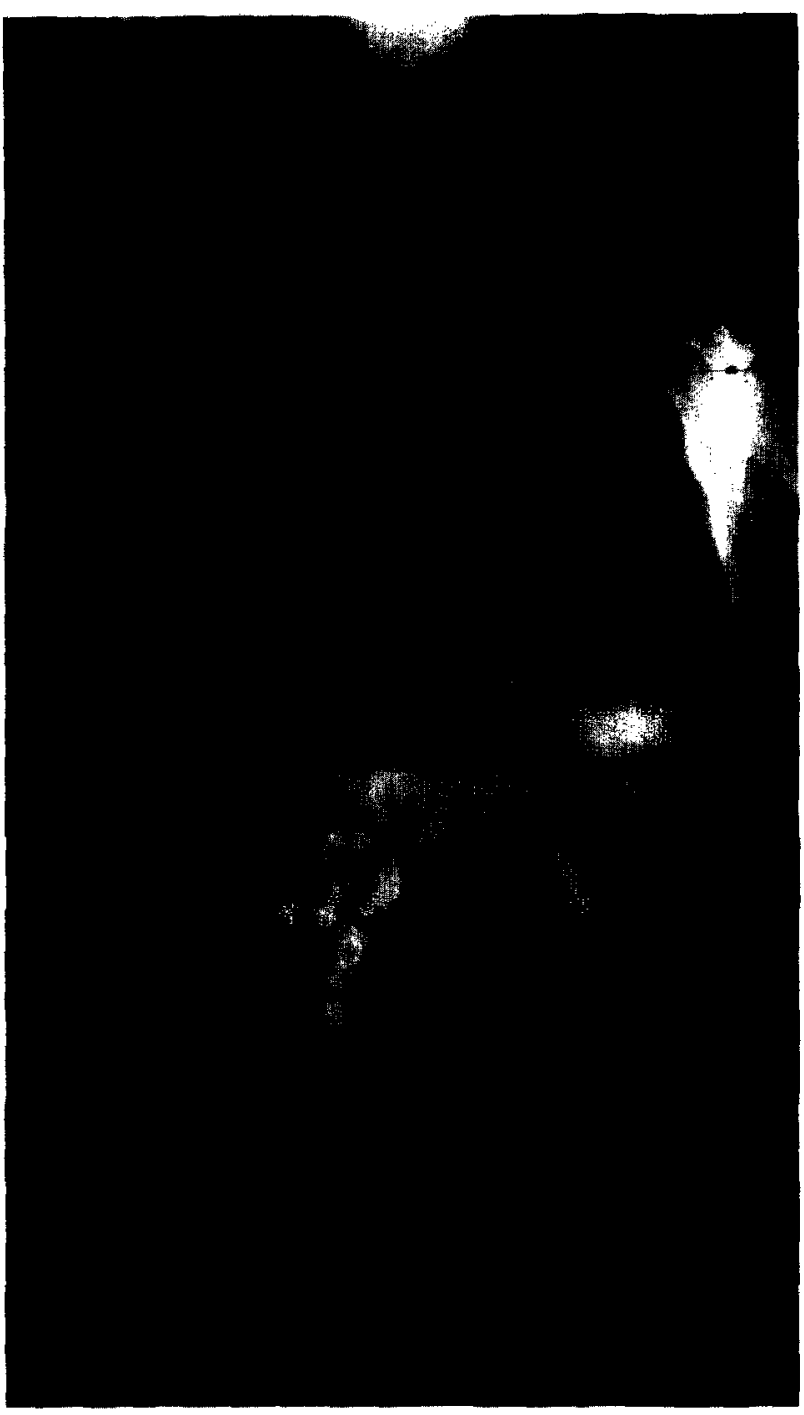

Fig 3. Anteroposterior spinal radiograph of a 13-year, 3-month-old girl with an omphalocele and vesicovaginal-rectal fistula. Notice the $70^{\circ}$ right thoracic scoliosis (T5-LY).

cal exstrophy). The period of organagenesis is also between the fourth and eighth week..$^{16}$ Thus, an insult that would lead to failure of body fold migration during the fourth week could also lead to other organ system malformations. This explains the higher incidence of associated anomalies in children with omphalocele compared with gastroschisis.

The development of a gastroschisis has been explained by two different theories. Hoyme et al ${ }^{17}$ believe that a thrombosis of the vitellointestinal artery could cause a gastroschisis and also explain the $15 \%$ incidence of associated intestinal atresia in these children. However, the vitellointestinal artery does not supply the ventral abdominal wall, and thus most authorities presently do not subscribe to this theory. ${ }^{15}$ Shaw ${ }^{18}$ feels that a gastroschisis comes from a rightsided rupture of the physiological umbilical hernia
Table 1. Musculoskeletal Problems in Children With Gastroschisis and Omphalocele

\begin{tabular}{|c|c|c|c|c|}
\hline \multirow[b]{2}{*}{ Problem } & \multicolumn{2}{|c|}{ Gastroschisis } & \multicolumn{2}{|c|}{ Omphalocele } \\
\hline & $\begin{array}{l}\text { No. of } \\
\text { Children }\end{array}$ & $\begin{array}{c}\text { No. With } \\
\text { Other Organ } \\
\text { System } \\
\text { Annmalies }\end{array}$ & $\begin{array}{l}\text { No. of } \\
\text { Children }\end{array}$ & $\begin{array}{l}\text { No. With } \\
\text { Other Organ } \\
\text { System } \\
\text { Anomalies }\end{array}$ \\
\hline \multicolumn{5}{|l|}{ Limb deformity } \\
\hline \multicolumn{5}{|l|}{ Arthogrypotic } \\
\hline Upper extremity & 1 & & 1 & 1 \\
\hline Lower extremity & 1 & & & \\
\hline \multicolumn{5}{|l|}{ Nonarthogrypotic } \\
\hline \multicolumn{5}{|l|}{ Congenital knee } \\
\hline subluxation & & & $1 \S$ & \\
\hline Phalangeal & 1 & & $\uparrow \ddagger$ & 1 \\
\hline \multicolumn{5}{|l|}{ Spinal deformity } \\
\hline Congenital & & & $1^{*}$ & 1 \\
\hline Developmental & & & 1 & 1 \\
\hline Spondylodysplastic & & & $1 \S$ & \\
\hline Athrogrypotic & 1 & 1 & $1^{*} \ddagger$ & 1 \\
\hline \multicolumn{5}{|l|}{ Metabolic } \\
\hline Osteopenia & 3 & 3 & & \\
\hline Pathologic fractures & $1 \dagger$ & $1+$ & & \\
\hline
\end{tabular}

* This child's deformity was a combined congenital/arthrogrypotic lordoscoliosis.

tThe one child with pathological fractures is included in the three with ostopenia.

$¥$, \$lndicate these deformities occurred in the same child

occurring at the site of the weaker involuting right umbilical vein. This explains the predominance of right-sided gastroschisis. This vein disappears in the sixth week. By this time, the major organ systems have

Table 2. Nonmusculoskeletal Problems in 66 Children With Gastroschisis and Omphalocele

\begin{tabular}{|c|c|c|}
\hline Organ System & $\begin{array}{c}\text { Gastraschisis } \\
(n=58)\end{array}$ & $\begin{array}{l}\text { Omphalocele } \\
(n-8)\end{array}$ \\
\hline \multicolumn{3}{|l|}{ Cardiopulmonary } \\
\hline Dextrocardia/VSD & & 1 \\
\hline PDA & 2 & \\
\hline Pulmonary hypoplasia & 1 & 1 \\
\hline Peripheral pulmonic stenosis & 1 & \\
\hline Pectus excavatum & & 1 \\
\hline \multicolumn{3}{|l|}{ Gastrointestinal } \\
\hline Atresia* & 7 & 1 \\
\hline Malrotation & 1 & \\
\hline Short-gut syndrome & 1 & \\
\hline \multicolumn{3}{|l|}{ Genitourinary } \\
\hline Hydronephrosis & 1 & 1 \\
\hline Cryptorchidism & 2 & 1 \\
\hline Vesicovaginal-rectal fistula & & 1 \\
\hline Total truncal exstrophy & & 1 \\
\hline \multicolumn{3}{|l|}{ Facial } \\
\hline Cleft palate & 1 & \\
\hline Other dysmorphic facies & 1 & \\
\hline \multicolumn{3}{|l|}{ Central nervous system } \\
\hline Seizures & 2 & \\
\hline
\end{tabular}

Abbreviations: VSD, ventricular septal defect; PDA, patent ductus arteriosus.

*The 7 gastroschisis atresias were 4 ileojujenal, 2 cecal/colonic, and 1 unspecified. The 1 omphalocele atresia was colonic. 
initially formed, explaining the lower incidence of associated anomalies in these children. The associated intestinal atresia in these children is felt to be the result of vascular obstruction to the intestines protruding through the defect.

Although both gastroschisis and omphalocele are known to have additional malformations, they are much more common in children with omphalocele. 3,6$8,15,19$ The incidence of associated congenital anomalies ranges from $5 \%$ to $39 \%$, $8,6,19$ in children with gastroschisis and from $38 \%$ to $66 \%$ 6,8,19 in children with omphalocele. Children with omphalocele also have an increased incidence of chromosomal abnormalities (eg, trisomy 13 or 18) and syndromes. . $^{6-8,15,19}$ Although the most common type of omphalocele is the lateral fold defect (also known as the central or epigastric type), $, 1,2,15$ they can also be superior or inferior to the umbilicus. ${ }^{1,6,7,15}$ These types are more often part of a syndrome and have a higher incidence of other congenital anomalies. The upper cephalic fold defect (also known as the upper midline omphalocele) is associated with sternal, diaphragmatic, pericardial and cardiac defects ${ }^{1,6,7}$ (Fig 2). A severe form is the pentalogy of Cantrell which consists of an epigastric omphalocele, a lower sternal cleft, anterior diaphragmatic and pericardial defects, and congenital cardiac lesions. ${ }^{14}$ The caudal fold defect (also known as the lower midline omphalocele) is an omphalocele associated with cloacal or bladder extrophy, imperforate anus, or colonic agenesis. ${ }^{1,6,7,15}$

The types of associated problems in children with omphalocele and gastroschisis include cardiac malformations (more common with omphalocele), intestinal atresias (more common with gastroschisis, especially jejunoileal), chromosomal abnormalities (more common with omphalocele), prematurity (more common with gastroschisis), and various other defects (facial anomalies, diaphragmatic hernias, cranial defects and hydrocephalus/hydromyelia, myeloceles and meningomyeloceles, and genitourinary anomalies). The types and frequencies in this series (Table 2) are similar to the other series mentioned above.

This is the first study to specifically look at musculoskeletal involvement in these children. Musculoskeletal anomalies have only been briefly mentioned in other series. Mayer et $\mathrm{al}^{6}$ described polydactylism in one child with an omphalocele, and bilateral hip dislocations, cloacal exstrophy and hydromyelia in another child with omphalocele. Klein et $\mathrm{al}^{2}$ noted musculoskeletal anomalies in 2 of 6 children with omphalocele and in 1 of 18 children with gastroschisis. The exact description of these anomalies was not given. Mabogunje and Mahour ${ }^{8}$ briefly mentioned orthopaedic problems in 1 child each with gastroschisis and omphalocele. Again the exact description was not given. $\mathrm{Kim}^{3}$ reported limb and vertebral anomalies in children with omphalocele; the exact incidence was not given. Stringel and Filler ${ }^{19}$ described meningoceles in 1 child each with gastroschisis and omphalocele but did not mention if they had associated orthopaedic involvement. Moore, ${ }^{7}$ in a literature review of 514 combined cases of gastroschisis and omphalocele, only alluded to 1 child with an unspecified musculoskeletal problem.

In this series of 66 children, there were 11 children (17\%) with 14 musculoskeletal problems. These musculoskeletal problems can be divided into anatomic deformities (either congenital or developmental) and metabolic problems. The metabolic problems were osteopenia secondary to malabsorption difficulties resulting from the underlying abdominal defect or rickets of prematurity, ${ }^{20}$ and associated with pathologic fractures in one child. Five of the congenital anatomic deformities were arthrogrypotic in nature and could be related to a decreased intrauterine space. Decreased intrauterine space from oligohydramnios, as seen in the prune-belly syndrome ${ }^{11}$ and Potter's syndrome, ${ }^{21}$ is felt to be the cause of severe deformities (arthrogryposis and associated clubfeet, dislocated hips, lower limb hemimelias, and others). A bicornate uterus or one with a fibroid that encroaches upon the available intrauterine space can also result in malformed limbs. ${ }^{22}$ We therefore postulate that eviscerated organs in the gastroschisis and omphalocele children decrease this space, resulting in arthrogrypotic-like deformitics.

Scoliosis is associated with arthrogryposis $(2.5 \%$ to $34 \%$ incidence) ${ }^{23}$ Herron et $\mathrm{al}^{23}$ found that one third of the patients in their series had scoliosis at birth while Daher et $\mathrm{al}^{24}$ noted this in one fifth of their patients. None had congenital vertebral anomalies. The curves often extended to the sacrum and were lordotic in nature. This was also similar to one of the two arthrogrypotic scolioses noted in this series. The other one in our series was associated with congenital vertebral and rib anomalies. This is similar to the pattern of curves noted by Drummond and MacKen$\mathrm{zie},{ }^{25}$ where one half of the children in their series had congenital vertebral anomalies.

Two of the anatomic deformities were defects in phalangeal development. These two phalangeal deformities correlate embryologically. One child with a gastroschisis had a partial syndactyly of the toes. The toe rays of the foot are just beginning to develop in embryos of 44 days gestation ( 6.3 weeks), but the foot plate is not yet definitely notched. ${ }^{26}$ Separation of the 
digits occurs shortly thereafter. A syndactyly can occur at this time. This also corresponds to the time of gastroschisis development as theorized by Shaw. ${ }^{18}$ The other child with a phalangeal deformity (absent distal phalanx of the thumb) had an omphalocele. The mesenchymal anlaga of the hand bones are formed between 33 and 41 days of gestation ( 4.7 to 5.8 weeks). This also correlates closely with the development of an omphalocele during the fourth week.

In this review, we specifically looked for the presence or absence of congenital spinal anomalies. The spinal mesenchymal anlaga form during the late fourth to sixth weeks of intrauterine life. ${ }^{9,16,27}$ It is known that congenital vertebral anomalies are associated with upper genitourinary anomalies, ${ }^{28-30}$ bladder and cloacal exstrophy, ${ }^{9,10}$ and imperforate anus. ${ }^{31}$ The development of the upper genitourinary system and cloacal division into the bladder and rectum also occur during the fourth to sixth weeks of intrauterine life, ${ }^{28-30.32-34}$ explaining this association. In this series, the only congenital vertebral anomaly occurred in a child with an omphalocele, which embryologically is presumed to occur during the fourth week of gestation. Since congenital vertebral anomalies occur during the fourth to sixth weeks of gestation, and since we encountered no congenital vertebral anomalies in any of the 58 children with gastroschisis which we reviewed, we feel this review supports the embryological origin of gastroschisis occurring after the sixth week.

A developmental deformity which could potentially occur in these children is that due to cerebral palsy. Up to $65 \%$ of children with gastroschisis are born premature.$^{6,8}$ Many cerebral palsy children are born premature or have fetal malformations. ${ }^{35,36}$ Although we surprisingly did not encounter any of these chil- dren developing cerebral palsy, it should be kept in mind by physicians when evaluating this group of children. We have no explanation for this finding.

In summary, this review of children with gastroschisis (58 cases) and omphalocele ( 8 cases) confirms the increasing incidence of gastroschisis (7.25:1 in this series, the highest reported to date). We have confirmed, as reported by others, the higher incidence of associated congenital anomalies in the children with omphalocele compared to those with gastroschisis. We have demonstrated 14 musculoskeletal problems in 11 children (17\%). Approximately one third of the problems $(5 / 14)$ were arthrogrypotic in nature and felt to be secondary to the abdominal wall defect and evisceration causing intrauterine space problems..$^{21,22}$ The remaining problems were congenital deformities of minor significance (eg, partial syndactyly); developmental metabolic problems from malabsorption difficulties directly related to the intestinal defects or prematurity, occasionally resulting in fractures; and late developmental orthopaedic deformities (eg, scoliosis in adolescence). The congenital deformities can be temporally related to the embryology of the particular abdominal wall defect. Finally, late problems can also occur (eg, scoliosis in adolescence) and the clinician should be aware of this. The new information from this study will enable those of us involved with these children to be aware of potential musculoskeletal problems and provide a better total care.

\section{ACKNOWLEDGMENT}

The authors would like to acknowledge the secretarial assistance of Lisa Janovits in preparing the manuscript and the help of $\mathrm{Dr}$ Arnold Coran in reviewing the manuscript.

\section{REFERENCES}

1. Klein MD, Hertzler JH: Congenital defects of the abdominal wall. Surg Gynecol Obstet 152:805-808, 1981

2. Klein MD, Kosloske A, Hertzler JH: Congenital defects of the abdominal wall. A review of the experience in New Mexico. JAMA 245:1643-1646, 1981

3. Kim SH: Omphalocele. Surg Clin North Am 56:361-371, 1976

4. Baird PA, MacDonald EC: An epidemiologic study of congenital malformations of the anterior abdominal wall in more than half a million consecutive live births. Am J Hum Genet 33:470-478, 1981

5. King DR, Savrin R, Boles ET Jr: Gastroschisis update. J Pediatr Surg 15:553-557, 1980

6. Mayer T, Black R, Matlak ME, et al: Gastroschisis and omphalocele. An eight-year review. Ann Surg 192:783-787, 1980

7. Moore TC: Gastroschisis and omphalocele: Clinical differences. Surgery 82:561-568, 1977

8. Mabogunje OA, Mahour GH: Omphalocele and gastroschi- sis. Trends in survival across two decades. Am J Surg 148:679-686, 1984

9. Greene WB, Dias LS, Lindseth RE, et al: Musculoskeletal problems in association with cloacal exstrophy. J Bone Joint Surg [Am] 73:551-560, 1991

10. Loder RT, Dayioglu MM: Association of congenital vertebral malformations with bladder and cloacal exstrophy. J Pediatr Orthop 20:389-393, 1990

11. Greskovich FJ III, Nyberg LM Jr: The prune belly syndrome: A review of its etiology, defects, treatment, and prognosis. J Urol 140:707-712, 1988

12. Tuch BA, Smith TK: Prune-belly syndrome. A report of 12 cases and review of the literature. I Bone Joint Surg [Am] 60:109-111, 1978

13. Thompson GH, Bilenker RM: Comprehensive management of arthrogryposis multiplex congenita. Clin Orthop 194:6-14, 1985

14. Cantrell JR, Holler JA, Ravitch MD: A syndrome of congenital defects involving the abdominal wall, sternum, dia- 
phragm, pericardium and heart. Surg Gynecol Obstet 107:602-614, 1958

15. Pringle PC: Abdominal wall defects and obstructive uropathies. Aetiology and management. Fetal Ther 3:67-83, 1988

16. Sadler TW: Langman's Medical Embryology (ed 6). Baltimore, MD, Williams \& Wilkins, 1990, pp 61-84

17. Hoyme HE, Higginbottom MC, Jones KL: The vascular pathogenesis of gastroschisis: Intrauterine interruption of the omphalomesenteric artery. J Pediatr 98:228-231, 1981

18. Shaw A: The myth of gastroschisis. J Pediatr Surg 10:235 244,1975

19. Stringel G, Filler RM: Prognostic factors in omphalocele and gastroschisis. J Pediatr Surg 14:515-519, 1979

20. Campbell DE, Fleischman AR: Rickets of prematurity: Controversics in causation and prevention. Clin Perinatol 15:879890,1988

21. Swinyard CA, Bleck EE: The etiology of arthrogryposis (multiple congenital contracture). Clin Orthop 194:15-29, 1985

22. Grahn JM, Miller ME, Stephan MJ, et al: Limb reduction anomalies and early in utero limb compression. J Pediatr 96:10521056,1980

23. Herron LD, Westin GW, Dawson EG: Scoliosis in arthrogryposis multiplex congenita. J Bone Joint Surg [Am] 60:293-299, 1978

24. Daher YH, Lonstein JE, Winter RB, et al: Spinal deformities in patients with arthrogryposis. A review of 16 patients. Spine 10:609-613, 1985

25. Drummond DS, MacKenzie DA: Scoliosis in arthrogryposis multiplex congenita. Spine 3:146-151, 1978
26. O'Rahilly R, Gardner E: The timing and sequence of events in the development of the limbs in the human embryo. Anat Embryol 148:1-23, 1975

27. Lonstein JE: Spinal embryology, in Winter RB (ed): Congenital Deformities of the Spine (ed 1). New York, NY, Theime Stratton, 1983, pp 1-10

28. MacEwen GD, Winter RB, Hardy JH: Evaluation of kidney anomalies in congenital scoliosis. J Bone Joint Surg [Am] 54:14511454,1972

29. Tori JA, Dickson JH: Association of congenital anomalics of the spine and kidneys. Clin Orthop 148:259-262, 1980

30. Vitko RJ, Cass S, Winter RB: Anomalies of the genitourinary tract associated with congenital scoliosis and congenital kyphosis. J Urol 108:655-659, 1972

31. Denton JR: The association of congenital spinal anomalies with imperforate anus. Clin Orthop 162:91-98, 1982

32. Diamond DA, Jeffs RD: Cloacal exstrophy: A 22-year experience. J Urol 133:779-782, 1985

33. Jeffs RD: Exstrophy and cloacal exstrophy. Urol Clin North Am 5:127-139, 1978

34. Muecke EC: Exstrophy, epispadias, and other anomalies of the bladder, in Walsh PF, Gittes RF, Perlmutter AD, et al, (eds): Campbell's Urology (ed 5). Philadelphia, PA, Saunders, 1986, pp 1856-1880

35. Nelson KB, Ellenberg JH: Antecedents of cerebral palsy. Multivariate analysis of risk. N Engl J Med 315:81-86, 1986

36. Paneth N: Etiologic factors in cerebral palsy. Pediatr Ann $15: 191-201,1986$ 